\title{
How to tell our stories
}

\author{
Writing about Patients: Responsibilities, \\ Risks, and Ramifications \\ Judy Leopold Kantrowitz \\ Other Press, 2006. 335 pp \$26.
}

I t's 3 o'clock, shift change at the retirement home, and the evening staff are getting report in the backroom while I sit at the nursing station, writing my note. The common area is empty except for Mrs. McLeod, who sits slumped in a geri-chair on the far side of the room. She has been given medication - too much in my opinion, because the nursing home is chronically understaffed and unable to cope with ambulatory patients with advanced dementia. My pen pauses. For a moment I look across the room at the tiny, frail woman and think of all the things I would like to say about her, about me, and the way we connect, or fail to, across this space.

Many doctors like to write about their experiences in medicine, myself included. In part, this is because people often write about what they know best, but there are many other reasons, ranging from the altruistic to the self-serving. We may have unconscious motivations for writing that we have never considered. And we don't always stop to think of all the ethical aspects of writing about our experiences, including the potential for harm. These are the issues addressed in Writing About Patients: Responsibilities, Risks and Ramifications.

In preparation for her book, Kantrowitz, an associate professor of psychology with the Department of Psychiatry at Harvard University, interviewed psychoanalysts regarding their views on writing about patients. Since Freud, the psychoanalytic literature has used detailed case descriptions of patients as clinical data. The biographical details of the history, the intimate thoughts of the patient, and the progress of the therapy are all considered relevant to understanding not only the individual patient, but universal processes. Psychoanalysis relies

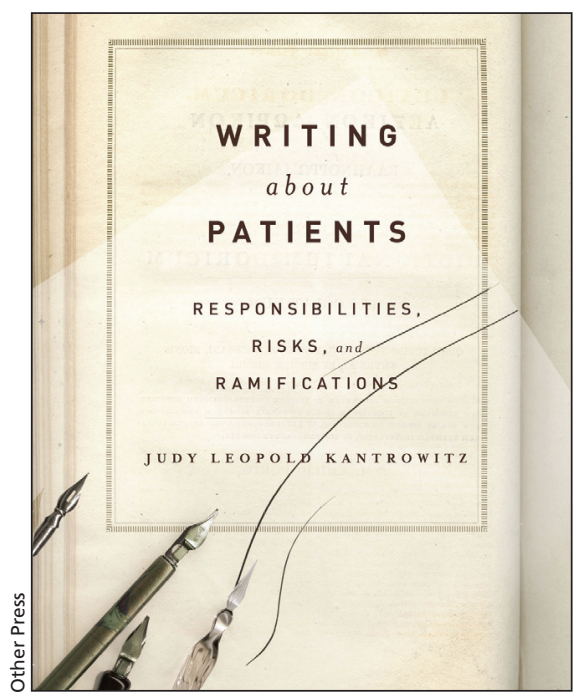

on narrative reports in a way that other schools of psychotherapy and most of the field of medicine do not, which can pose problems with patient confidentiality. For one thing, changing details to disguise the identity of a patient or creating composite patients can be misleading: a certain degree of fidelity to the details of a case is necessary so other analysts can decide if they agree with the author's conclusions.

On the other hand, analysts are very conscious that asking for permission to publish a patient's case history might affect the relationship between therapist and patient. The alternative is that harm might be done if the patient inadvertently read a case description and recognized him or herself. Kantrowitz describes how analysts struggle with whether (and when) to ask permission to write about a patient, as well as other issues such as understanding their own motivation, or how their biases may be present in their writing. The arguments on all sides of these difficult questions illustrate how complex the process is and the paucity of easy solutions.

Even though the same adherence to the facts of a case is not required in most of the creative writing that physicians do, there is still the issue of representing life authentically. Any physician who has struggled with how to write about medi- cine in a considered, honest way without compromising the privacy of patients, or the veracity of experience, should find this book to be a thought-provoking read.

Mrs. McLeod would never be able to understand why I want to write about her. I wonder if I even understand it myself. I might say that it's because I don't want people like her to be neglected or forgotten, that I want other physicians to read what I write and look on their own patients with a greater degree of compassion. I could speak of advocacy or of art, with equal conviction. But perhaps I just want to sort out my own feelings of pity, guilt, fear or indifference. Maybe I want others to understand me even more than Mrs. McLeod. Perhaps I am trying to immortalize my own words because it's me who I don't want to be forgotten, not her.

I could call her family to explain that I want to include her in a book review I am writing. Or if I didn't want the awkwardness of asking permission, I could change her gender, her age, her name, her diagnosis. I could combine 2 patients into 1 flesh. Or I could go one step further and create her, and indeed this whole scenario, out of my imagination and my knowledge of a hundred women like her in a dozen nursing homes I have visited over the past 6 years. As in fact I have just done.

At some point, the line between fact and fiction gets blurred. Perhaps I should have chosen to leave Mrs. McLeod out of this entirely and written the book review without her. But as physicians, many of our experiences involve patients and if we are to tell our own stories, there will be patients in them. The question is how to tell these stories in a way that is respectful to our patients and beneficial to our field. In this thoughtful book, Kantrowitz helps us to consider how we might work toward this goal.

\section{Lara Hazelton MD}

\section{Psychiatrist}

Halifax, NS 